\title{
ROMANIA AND THE KNOWLEDGE-BASED ECONOMY: INNOVATION THE SOURCE OF ECONOMIC GROWTH
}

\author{
PhD student Holban (Oncioiu) Ionica, Alexandru Ioan Cuza University of Iasi and Academy of \\ Economies Studies from Bucharest, Email: nelly_oncioiu@yahoo.com \\ PhD student Oncioiu Florin Razvan, University of Agronomic Sciences and Veterinary Medicine of \\ Bucharest, Email: oncioiu_florin@yahoo.com
}

\begin{abstract}
The is already a vast literature on the role of knowledge in economic growth but there is need to clarify the meaning and scope of this term and define the Romanian perspective on the relationship between knowledge-based economy and growth.

This paper focuses on innovation systems in Romania as the key challenge and mean for embracing growth based on knowledge-based economy.
\end{abstract}

Keywords: innovation, economic growth, knowledge

JEL Code: O32,Q55

The knowledge-based economy is a controversial term which nevertheless describes the important changes to the nature of growth and catch-up that have been taking place at the beginning of the twenty-fist century. It has been defined in different ways, all of which highlight the increasing importance of knowledge as a source of growth. OECD (1996) defines knowledge-based economy as 'economies which are directly based on the production, distribution and use of knowledge and information'. Also Dahlman and Andersson (2000) defines knowledge-based economy as 'one that encourages its organizations and people to acquire, create, disseminate and use (codified and tacit) knowledge more effectively for greater economic and social development'. So, this definition shows to the increasing dependence of economies on the effective creation, acquisition, distribution and use of knowledge.

Very often the definition of knowledge is imported from the theoretical models when economic policy-making is concerned, ignoring its rather different empirical manifestation. For example, the multifactor residual method does not provide a clear guide to what an appropriate growth-driving policy action would be. The method of Stiglits considers the relation between the suppliers and the customers as information relevant only in relation to the current market situation and not in relation to the potential value following possible future. Another method is focusing on an integrated vision where the individual elements stimulate knowledge creation and incorporate into goods or services. We mean there the definition provided by the Word Bank which divides the knowledge-based economy as follows:

1. an economic and institutional regime that provides incentives for the efficient use of existing and new knowledge ;

2. an educated and skilled population that can create, share and use knowledge well;

3. a dynamic information infrastructure that can facilitate the effective communication, dissemination and processing of information;

4. an efficient innovation system that can tap into the growing stock of global knowledge, assimilate and adapt it to local needs and create new technology.

From these examples result clear that although the role of knowledge for economic growth is largely accepted and the way these mechanisms could be directly stimulated. 
There are three concepts regarding policy measures of innovation which can be relevance in the case of Romania:

1. innovation as recombination concept promoted by Schumpeter;

2. innovation without research concept promoted by Cowan and Gert van de Paal;

3. the utilitarian vision of knowledge.

Innovation as recombination is equally economic optimization issue and result is generated from a combination of already known elements or factors. Based only on access to information and on accumulated experience, innovation without research recombines knowledge in order to optimize the information which is not based on formalized research. The new knowledge is largely based on the old knowledge because the simplest way of stimulating the creation of new knowledge is to make the old knowledge visible. The characteristic of the visibility derives from the close connection between the knowledge content and its interface. A larger visibility reduces the information asymmetry and the associated transaction costs.

According with Piech (2004) problems over the concept of knowledge-based economy emerge when attempting to measure defines knowledge-based activities. This is a far from trivial task due to several specific features of knowledge and the costs of them are marginal, but that does not mean all knowledge is transferable. Some of this knowledge could be codified, but truly tacit knowledge cannot be codified under any conditions due its highly informal or person-embodied character. Codification, or the conversion of complex knowledge into user-friendly information, has become economically very important in all sectors in Romania.

The Romanian decision factors must understanding that externalization of knowledge and its storage in various new knowledge objects create new cognitive potentials. How to manage such knowledge is one of the competencies required in the knowledge economy. Practical the value of knowledge depends greatly on the cognitive capabilities of the recipients of the knowledge. The technical opportunity to amass and process large amounts of information at very low cost has potentially far-reaching effects on all economic activities. In this context productivity growth in new sectors is an important feature of structural change.

As a consequence, in Romania was created a vicious circle where the state is ensuring the minimum financial resources for stimulation of knowledge-based economy and only a few companies proved able to compete through innovation. Very often knowledge is strongly connected with people and all or part of it can do a major challenge. Innovation system is important for clarifying the area of innovation policy and also for fostering the interactions.

According to the statistics of Ministry of Education and Research until 2002 a number of 590 units were involved in the innovation system. Out of which 280 were research and development institutes and 310 joint-stock companies (public or private) with research -development as the main object of activity. Since 2003 the situation of research system was improve because, on the hand, Romania became a member of the European Patent Convention in March and, on the other hand, the Government took the Decision 406/2003 where there are present specific conditions regarding the eligibility of a firm or a department of research institution to be considered as an innovation entity. In the document is specifically that the applicants for such a status provide certain documentation in order to be accepted. So, being with that decision an innovation entity can be called innovation infrastructure unit, practical a new concept was introduced refers to technological transfer centers which are financed through a governmental program. That initiative is very important for creating the visibility of the entity which wants to invest in innovation. The current situations of Romania are highly dependent upon the visibility level and the research system includes the research institutes, the research departments of universities, and research departments of the companies.

The specific situation in Romania regarding the research system was considered to be the only policy element, so, research and innovation are not approached as different process that 
address distinct markets and have a different timelines. This does not mean that the research units are able to move on the global technological frontier and increase their chances to apply innovation.

The initiative to the governmental level of innovative process based on the market strategies have the most important role in transforming the visible knowledge into marketable products and representing the economic opportunity of recombining knowledge. At top of that, more and more companies have involving in different stage of the innovation process. In order to stimulate the companies to start their learning process, the first necessary step is to ensure a higher visibility of the economic benefits that knowledge incorporation brings about.

In this direction in Romania the capital and financial channels for innovation activities can be the private venture capital. The availability of that capital does not depend only on financial issues, but also on other factors as follows:

1. the risk propensity;

2. the provider's capacity for technical evaluation;

3. the provider's insertion on the innovation market.

The innovation infrastructure includes: incubators (infrastructure for start-ups), technological parks (experimental facilities), technical transfer centers and the system of intellectual property. Regarding the infrastructure the government consistent policy measures according to the recently launched National Plan for Developing the Infrastructure for Innovation and Technological Transfer. In this plan is mentioning the amount which is destined to co-finance centers of technological transfer, office for connection with industry, technological parks and technological incubators.

Ministry of Education and Research and the Ministry of Communications and Information Technology aim to attract to industrial parks with intention to create such parks in every Romanian city that has a university centre. They estimate that around 50 business incubators have been created, but there are no monitoring mechanisms and no efficiency criteria or targets for them.

The whole set of documents released by the Romanian authorities regarding the evolution of research, development and innovation systems does not even address the issue of patents and it was only in 2004 that the grants are made conditional on patent applications.

In conclusion, the major challenge is to extend the area of innovation especially in the software industry where Romania has an advantage. But this is only the fist step in this process for all parts involved. So, the state institutions have an important role in order to expand the visibility rules.

\section{References:}

1. Cowan R. and G. Van de Paal - Innovation Policy in a Knowledge-Based Economy, a MERIT study commissioned by the European Commission, 2000.

2. Gamureac, S. - Innovation Policy in Seven Candidate Countries: The Challanges. Innovation Policy Profile: Romania, study coordinated by ADE, Louvain la Neuve, EC, 2003.

3. Gheorghiu R., D. Pislaru and G. Turlea - The innovation-based Competitivness of the Romanian Economy in the Framework of the Lisbon Strategy, financed by the Open Society Institute (OSI Budapest), part of Costs and benefits of Romania's EU accession - a public education project, 2004.

4. Kay J. - What became of the New Economy?, National Institute Economic Review, No 177, July 2001.

5. National Institute of Statistics - Innovation in Industriy and Services during 2000-2002, Bucharest, 2005.

6. Romanian Statistical Yearbook, Bucharest, National Statistical Ofiice, 2003.

7. Schwab K., M. E. Porter and P.K. Cornelius - The Global Competitivness Report 20022003, London and New York, World Economic Forum - Oxford University Press. 